\title{
Role of Socio-demographic, Lifestyle, Psychological and Anthropometric Parameters on Cardiovascular Disease Risk Among Mashad Cohort Study Population
}

\section{Zahra Asadi}

Mashhad University of Medical Sciences

Hamideh Ghazizadeh

Mashhad University of Medical Sciences

Mahdieh Yaghooti

Mashhad University of Medical Sciences

Moniba Bijari

Mashhad University of Medical Sciences

Hamed Khedmatgozar

Mashhad University of Medical Sciences

Ali Ebrahimi Dabagh

Mashhad University of Medical Sciences

Mohammad Amin Mohammadi

Mashhad University of Medical Sciences

Mohammad Reza Fazl

Mashhad University of Medical Sciences

Shadi Kadkhoda-Ahmadi

Mashhad University of Medical Sciences

\section{Sara Moazedi}

Mashhad University of Medical Sciences

Arezoo Rastegar-Moghadam

Mashhad University of Medical Sciences

Reza Zare-Feyzabadi

Mashhad University of Medical Sciences

Fatemeh Sadabadi

Mashhad University of Medical Sciences

Susan Darroudi

Mashhad University of Medical Sciences

Habibollah Esmaily

Mashhad University of Medical Sciences 


\section{Maryam Tayefi}

Mashhad University of Medical Sciences

Mohsen Moohebati

Mashhad University of Medical Sciences

Alireza Heidari-Bakavoli

Mashhad University of Medical Sciences

Gordon A. Ferns

brighton and sussex medical school

Majid Ghayour-Mobarhan ( $\nabla$ ghayourm@mums.ac.ir)

Mashhad University of Medical Sciences

Original investigation

Keywords: Cardiovascular disease, Metabolic syndrome, Diabetes mellitus, Hypertension

Posted Date: June 22nd, 2020

DOI: https://doi.org/10.21203/rs.3.rs-35931/v1

License: (c) (1) This work is licensed under a Creative Commons Attribution 4.0 International License.

Read Full License 


\section{Abstract}

\section{Introduction:}

Cardiovascular disease (CVD) is the leading cause of mortality and one of the main challenges for health systems worldwide. In this study, we aimed to evaluate the role of socio-demographic, lifestyle, psychological factors, anthropometric measurements, and presence of underlying diseases in CVD progression among a subpopulation of Iranian adults.

\section{Methods}

A total of $235 \mathrm{CVD}$ patients were enrolled. The control group also included healthy and non-symptomatic individuals ( $n=8405)$. Health and lifestyle questionnaires, the Beck's anxiety inventory (BAI), Beck's depression inventory (BDI) and the James and Schofield human energy requirements equations were completed for all participants. Anthropometric measurements were also evaluated in all subjects.

\section{Results}

After six years of follow-up, we found that there were significant positive correlations between CVD risk and age, body mass index (BMI), waist circumference (WC), waist-to-height ratio (WHtR), diabetes mellitus (DM) and family history (FH) of CVD in both genders; though, there was a significant negative correlation between physical activity level (PAL) and risk of CVD among men and women. Also hypertension (HTN), metabolic syndrome (MS), depression and anxiety were positively and higher education level was negatively associated with CVD events only in females. While, waist-to-hip ratio (WHR) was an independent predictor of CVD among males.

\section{Conclusion}

There are several modifiable and non-modifiable risk factors that were independently considered as CVD predictors among the MASHAD study population. It is recommended that the lifestyle modifications, development of local risk calculators and gender-related stratified strategies should be prioritized in order to prevent and manage CVD among the Iranian population.

\section{Introduction}

Cardiovascular disease (CVD) is the leading cause of mortality and morbidity worldwide (1). CVD accounts for 17.3 million deaths per year in 2015 (2) which is more deaths than caused by all nutritional, communicable, neonatal and maternal disorders combined (3). It is estimated that the mortality rate from CVD grows to more than 23.6 million by 2030 with a total direct medical cost of $\$ 749$ billion in 2035 (2, 4). Although the incidence rate of CVD has been shown to have a declining pattern in developed 
countries, it is still a growing concern among developing countries such as Iran $(5,6)$. CVD is responsible for about $50 \%$ of total deaths in Iranian population annually (7); including ischemic heart disease (26\% in both genders), stroke (10\% in men, $13 \%$ in women), hypertensive heart disease (5\% in both genders) and other CVDs (5\% in men and $6 \%$ in women) (8). CVD prevention is the most important step to eliminate and minimize the disease impact and its related disabilities (9). Risk assessment and identification of high-risk populations and individuals allow early preventive strategies and should be considered by health politicians (9). Nevertheless, risk estimation methods that are clinically utilized in a particular country or ethnicity may not be useful for the other populations $(9,10)$

CVD is known to have many bio-psycho-social and genetic factors with complex interactions. However Age, diabetes mellitus (DM), total cholesterol (TC), low and high-density lipoprotein cholesterol (LDL-C and HDL-C), blood pressure, metabolic syndrome (MS) and smoking are well-known risk factors for CVD $(11-17)$. There are different patterns of these risk factors and their interactions among different populations (18). There are a higher incidence of stroke and its related risk factors among the Iranian population compared to the western countries (19). One study in Sweden showed that the immigrant Iranian women had higher body mass index (BMI), abdominal obesity, risky lipid profile and lower physical activity and therefore higher incidence of CVD compared to the Swedish women (20). This variation can be explained by the role of genetic, ethnic and socioeconomic differences. This raises the priority of local population-based studies on CVD risk factors in order to develop regional risk assessment methods and population-based policies.

The Mashhad stroke and heart atherosclerotic disorder (MASHAD) study were started in 2010 with the aim of investigating the determinants and risk factors of atherosclerotic CVD in a north-eastern population of Iran. This study aims to investigate the association of socio-demographic, lifestyle, psychological and anthropometric factors and underlying diseases such as hypertension, DM and MS with CVD risk in this population after six years of follow-up.

\section{Methods}

\section{Study population}

The Mashhad stroke and heart atherosclerotic disorder (MASHAD) study was a large longitudinal prospective cohort study which was started in 2010 and will be continued until 2020 . The aim of this study was to determine the prevalence of CVD and its biological, environmental, social, and behaviorrelated risk factors in Mashhad, north-eastern Iran. Using a stratified cluster random sampling method, 9704 healthy individuals who were free of CVD and the other chronic diseases with the age between 35 to 65 years were recruited from three regions in Mashhad. Informed consent was obtained from all participants. Comprehensive information on design and baseline characteristics of the MASHAD study population was published in 2015 (21). The subjects were followed up in 2011, 2014 and 2016. In the third follow-up, the study participants were followed up from April 2015 to May 2016 and 235 patients were diagnosed with CVD. The individuals with incomplete data $(n=88)$ and those who did not take part 
in different stages of follow-up $(n=1152)$ were excluded from the present analysis. Eventually, a total of 8640 participants were enrolled in the current study including 235 patients who developed CVD (120 patients with unstable angina, 75 patients with stable angina, and 40 patients with myocardial infarction $(\mathrm{MI}))$, and the healthy and non-symptomatic individuals $(n=8405)$ as the control group. The study was approved by the Ethics Committee of Mashhad University of Medical Sciences.

\section{Blood sampling}

According to a standard protocol, all the blood samples were taken from the antecubital vein and midstream urine was collected from all the participants. Further details on laboratory measurement are explained in the baseline report of the MASHHAD cohort study.

\section{CVD Diagnosis}

A baseline 12-lead electrocardiogram (ECG) was performed for each participant. All ECGs were read blindly by the Minnesota codes and were stored digitally for subsequent analysis. The presence of CVD was corroborated by a history of MI or angina pectoris or electrocardiographic evidence for a definite Q wave in the third follow-up $(22,23)$. Medical history assessment and physical examination were done by a cardiologist and the Framingham cardiovascular examination questionnaire was also completed for the entire population (24). Furthermore, participants with suspected CVD were examined by echocardiography, stress echocardiography, radioisotope, angiography, Computed Tomography (CT) angiography, and Exercise Tolerance Test (ETT).

\section{Disease criteria}

DM was defined as an fasting blood glucose $(\mathrm{FBG}) \geq 126 \mathrm{mg} / \mathrm{dl}$ or being under insulin therapy or consuming oral hypoglycemic agents (18). Hypertension (HTN) was diagnosed in individuals with systolic blood pressure (SBP) at or above $140 \mathrm{mmHg}$ and/or diastolic blood pressure (DBP) at or above $90 \mathrm{mmHg}$, and in persons who were on antihypertensive medication (25). Dyslipidemia was defined as $\mathrm{TC} \geq 200 \mathrm{mg} / \mathrm{dl}(5.18 \mathrm{mmol} / \mathrm{l}), \mathrm{LDL}-\mathrm{C} \geq 130 \mathrm{mg} / \mathrm{dl}$ ( $3.36 \mathrm{mmol} / \mathrm{l})$, or triglyceride $(\mathrm{TG}) \geq 150 \mathrm{mg} / \mathrm{dl}$ $(1.69 \mathrm{mmol} / \mathrm{l})$, or HDL-C $<40 \mathrm{mg} / \mathrm{dl}(1.03 \mathrm{mmol} / \mathrm{l})$ in men and $<50 \mathrm{mg} / \mathrm{dl}(1.30 \mathrm{mmol} / \mathrm{l})$ in women (26). Metabolic syndrome (MS) was described according to the joint interim statement of the International Diabetes Federation (IDF) task force on epidemiology and prevention on 2009 criteria:FBG $\geq 100 \mathrm{mg} / \mathrm{dl}$, blood pressure (BP) $\geq 130$ /85 mmHg; High-density lipoprotein cholesterol (HDL-C) $<50 \mathrm{mg} / \mathrm{dl}$ for women or $<40 \mathrm{mg} / \mathrm{dl}$ for men; triglyceride (TG) $\geq 150 \mathrm{mg} / \mathrm{dl}$; and waist circumference (WC) $\geq 80 \mathrm{~cm}$ for women or $\geq 94 \mathrm{~cm}$ for men (27). MS patients were those who had at least three or more components of this criteria (28).

Smoking habits were classified as current smoker (daily smoking of at least one cigarette), ex-smoker (formerly a daily smoker, but does not smoke currently) and non-cigarette smoker.

\section{Data collection}


In order to determine any changes in the health state and lifestyle, a comprehensive questionnaire was completed for all participants by skilled interviewers and all necessary information including the patient socio-demographic characteristics and lifestyle factors (physical activity level [PAL], and tobacco use were gathered. Beck's anxiety inventory (BAI) and Beck's depression inventory (BDI) were performed to evaluate the presence of anxiety and depression in our participants $(29,30)$. The James and Schofield human energy requirements equations were used to estimate PAL (31). The PAL assessment was measured in three days' time zones including working time (including housework), non-working time, and resting/sleeping time. Anthropometric parameters including BMI, height, weight, WC, hip circumference (HC), waist-to-hip ratio (WHR), waist-to-height ratio (WHtR), demispan and mid-arm circumference (MAC) were evaluated in all the subjects as described before $(32,33)$. Blood pressure measurements were also done three times with a 30 minutes interval by two certified health care professionals and a certified nurse using a sphygmomanometer. The averaged of the two closest measurements was reported as the final blood pressure. SBP and DBP were determined from the left arm (after 15 minutes of resting) (34).

\section{Statistical analysis}

Data analysis was carried out using SPSS 16.0 software (SPSS Inc., Chicago, IL, USA). Descriptive statistics including mean, frequency, percentage, variance and standard deviation (SD) were determined for all variables and expressed as mean \pm standard deviation (SD) and frequency (percentage) for continuous and categorical variables, respectively. Moreover, the chi-square and Student t-test were used to compare the clinical characteristics and baseline demographics between two groups for normally distributed variables. Cox regression analyses were used to calculate the hazard ratio (HR) and 95\% confidence interval $(\mathrm{Cl})$ of $\mathrm{CVD}$ risk. The $\mathrm{HR}$ and $95 \% \mathrm{Cl}$ were adjusted for significant parameters obtained by a univariate model including age, diabetes mellitus and family history (FH) of cardiovascular disease. A $P$-value $<0.05$ was considered as significant.

\section{Results}

\section{Baseline characteristics}

The baseline characteristics of the participants sorted by the incidence of CVD are shown in Table.1. The participants with developed CVD were significantly older, with lower educational level, higher frequency of smoking and lower PAL compared to those with no CVD event ( $P=0.001$ for PAL and $<0.001$ for others). According to the anthropometric measurements, parameters such as weight, BMI, WC, WHR, and WHtR were significantly higher among patients with CVD compared to healthy controls ( $P$ was 0.01 for weight, 0.001 for $\mathrm{BMI}$ and $<0.001$ for others). As expected, the prevalence of chronic disorders such as diabetes mellitus (DM), hypertension (HTN), dyslipidemia, MS, depression and anxiety scores and also prevalence of family history (FH) of CVD were higher among CVD patients $(P<0.01)$.

Association of various risk factors with CVD event among men and women of the study (Table 2) 
Table 1

Comparing baseline characteristics of study participants based on cardiovascular disease incidence.

Variables

Cardiovascular disease

P-value

No $(n=8405) \quad$ Yes $(n=235)$

Socio-demographics

Age (year)

$47.88 \pm 8.11$

$54.26 \pm 6.96$

$<0.001$

Marital status

93.80 (8774)

92.30 (217)

0.361

Married

$6.20(521)$

$7.70(18)$

Single/divorced/widow

Education (year)

$8.15 \pm 4.91$

$6.66 \pm 4.78$

$<0.001$

Lifestyle factors

Smoking status

69.60 (5846)

$61.30(144)$

$<0.001$

Non smoker

9.80 (820)

$17.40(41)$

Ex-smoker

20.70 (1739)

$21.30(50)$

Current smoker

PAL

$1.59 \pm 0.28$

$1.53 \pm 0.28$

0.001

Anthropometric measurements

Height $(\mathrm{cm})$

Weight (kg)

BMI $\left(\mathrm{kg} / \mathrm{m}^{2}\right)$

WC (cm)

$\mathrm{HC}(\mathrm{cm})$

WHR
$160.81 \pm 0.09$

$71.88 \pm 12.84$

$27.84 \pm 4.70$

$95.11 \pm 12.01$

$103.66 \pm 9.26$

$0.92 \pm 0.08$
$160.31 \pm 0.09$

0.407

$74.07 \pm 12.50$

$28.87 \pm 4.56$

0.010

0.001

$98.97 \pm 10.68$

$<0.001$

$104.20 \pm 9.50$

0.378

$0.95 \pm 0.07$

$<0.001$

Abbreviations: PAL: physical activity level; BMI: body mass index; WC: waist circumference; HC: hip circumference; WHR: waist-to-hip ratio; WHtR: waist-to-height ratio; MAC: mid-upper arm circumference; CVD: cardiovascular disease; DM: diabetes mellitus; HTN: hypertension; MS: metabolic syndrome.

Data presented as mean \pm standard deviations or median (interquartile range). Independent sample ttest was used where appropriate.

The data of education $(n=38)$, WC $(n=7)$, WHR $(n=7)$, MAC $(n=4)$, demispan $(n=19)$, BFP $(n=486)$, $\operatorname{SBP}(n=1), \operatorname{DBP}(n=1), \operatorname{FBG}(n=4), T C(n=2), T G(n=2), \operatorname{LDL}-C(n=3), \operatorname{HDL}-C(n=3)$, uric asid $(n=3)$, $\operatorname{WBC}(n=113), \operatorname{RBC}(n=112), \operatorname{HGB}(n=112), \operatorname{HCT}(n=112), \operatorname{MCV}(n=112) \operatorname{MCH}(n=171), \operatorname{MCHC}(n=$ $112)$, PLT $(n=179)$, family history of CVD $(n=71), \operatorname{DM}(n=4), \operatorname{HTN}(n=1)$, dyslipidemia $(n=4)$, and MS $(n=3)$ were missed for study participants. 


\begin{tabular}{|c|c|c|c|}
\hline \multirow[t]{2}{*}{ Variables } & \multicolumn{2}{|c|}{ Cardiovascular disease } & \multirow[t]{2}{*}{ P-value } \\
\hline & No $(n=8405)$ & Yes $(n=235)$ & \\
\hline WhtR & $0.59 \pm 8.23$ & $0.62 \pm 7.75$ & $<0.001$ \\
\hline MAC (cm) & $30.58 \pm 3.94$ & $30.59 \pm 3.61$ & 0.960 \\
\hline Demispan (cm) & $76.94 \pm 5.59$ & $76.82 \pm 6.32$ & 0.758 \\
\hline \multicolumn{4}{|l|}{ Disease characteristics } \\
\hline Family history of CVD & $34.90(2912)$ & $44.60(103)$ & 0.002 \\
\hline DM & $8.30(698)$ & $27.90(65)$ & $<0.001$ \\
\hline HTN & $22.60(1900)$ & $44.40(104)$ & $<0.001$ \\
\hline Dyslipidemia & $85.20(7164)$ & $91.40(212)$ & 0.009 \\
\hline MS & $14.90(1251)$ & $39.10(91)$ & $<0.001$ \\
\hline \multicolumn{4}{|l|}{ Psychological factors } \\
\hline Depression score & $12.28 \pm 9.53$ & $14.06 \pm 9.41$ & 0.005 \\
\hline Anxiety score & $10.39 \pm 9.72$ & $12.78 \pm 10.98$ & $<0.001$ \\
\hline \multicolumn{4}{|c|}{$\begin{array}{l}\text { Abbreviations: PAL: physical activity level; BMI: body mass index; WC: waist circumference; HC: hip } \\
\text { circumference; WHR: waist-to-hip ratio; WHtR: waist-to-height ratio; MAC: mid-upper arm } \\
\text { circumference; CVD: cardiovascular disease; DM: diabetes mellitus; HTN: hypertension; MS: metabolic } \\
\text { syndrome. }\end{array}$} \\
\hline \multicolumn{4}{|c|}{$\begin{array}{l}\text { Data presented as mean } \pm \text { standard deviations or median (interquartile range). Independent sample t- } \\
\text { test was used where appropriate. }\end{array}$} \\
\hline \multicolumn{4}{|c|}{ 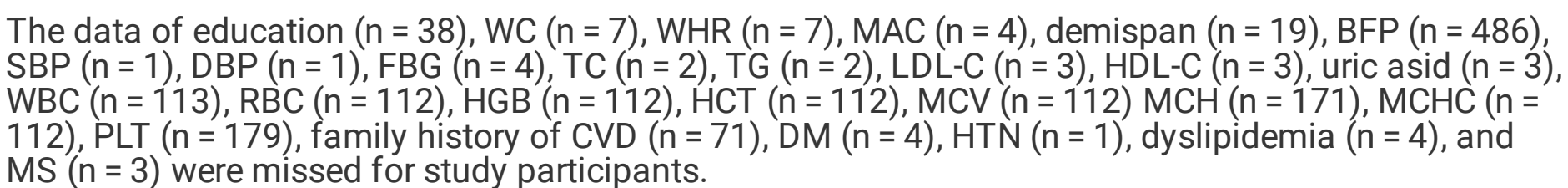 } \\
\hline
\end{tabular}


Table 2

Adjusted HRs of developing cardiovascular disease according to different risk factors.

Variable

Male $(n=3560)$

Female $(n=5080)$

$\mathrm{HR}$

$95 \% \mathrm{Cl}$

P- $\quad H R$

value

$95 \% \mathrm{Cl}$

P.

value

\section{Socio-demographics}

\begin{tabular}{|c|c|c|c|c|c|c|}
\hline Age (year) & 1.08 & $\begin{array}{l}1.05- \\
1.11\end{array}$ & <. 001 & 1.11 & $\begin{array}{l}1.08- \\
1.14\end{array}$ & $\begin{array}{l}<.001 \\
0.00\end{array}$ \\
\hline \multirow{2}{*}{$\begin{array}{l}\text { Marital status } \\
\text { Married }\end{array}$} & $\begin{array}{l}1 \\
\text { (reference) }\end{array}$ & $\begin{array}{l}0.12- \\
6.33\end{array}$ & 0.901 & $\begin{array}{l}1 \\
\text { (reference) }\end{array}$ & $\begin{array}{l}0.73- \\
2.15\end{array}$ & 0.403 \\
\hline & \multicolumn{3}{|l|}{0.88} & \multicolumn{3}{|l|}{1.26} \\
\hline
\end{tabular}

Single/divorced/widow

Education (year)

$\begin{array}{ll}1 & 0.97- \\ & 1.04\end{array}$

0.829

0.93

$0.89-$

0.98

0.002

\section{Lifestyle factors}

Smoking status

$\begin{array}{ll}1 & 0.99- \\ \text { (reference) } & 2.55\end{array}$

Non smoker

$1.59 \quad 0.85-$

0.055

1

$0.80-$

0.230

(reference) $\quad 2.50$

0.772

Ex-smoker

1.35

2.15

1.42

$0.67-$

1.07

1.73

Current smoker

PAL

0.40

$0.18-$

0.018

0.28

$0.11-$

0.006

0.85

0.70

\section{Anthropometric measurements}

Height

0.18

$0.01-$

0.237

1.75

0.08

3.06

37.52

Weight

1.01

$1-1.03$

$0.102 \quad 1.01$

$1-1.03$

0.056

Abbreviations: PAL: physical activity level; BMI: body mass index; WC: waist circumference; HC: hip circumference; WHR: waist-to-hip ratio; WHtR: waist-to-height ratio; MAC: mid-upper arm circumference; CVD: cardiovascular disease; DM: diabetes mellitus; HTN: hypertension; MS: metabolic syndrome; HR: hazard ratio, Cl: confidence interval.

Data presented as mean \pm standard deviations or median (interquartile range). Independent sample ttest was used where appropriate.

The data of education $(n=38)$, WC $(n=7)$, WHR $(n=7)$, MAC $(n=4)$, demispan $(n=19)$, WBC $(n=113)$, family history of CVD $(n=71), \operatorname{DM}(n=4), \operatorname{HTN}(n=1)$, dyslipidemia $(n=4)$ and MS $(n=3)$ were missed for study participants.

† HR was adjusted for age and significant parameters in univariate (including diabetes mellitus and family history of cardiovascular disease). 


\begin{tabular}{|c|c|c|c|c|c|c|}
\hline \multirow{2}{*}{$\begin{array}{l}\text { Variable } \\
\text { BMI }\end{array}$} & \multicolumn{3}{|c|}{ Male $(n=3560)$} & \multicolumn{3}{|c|}{ Female $(n=5080)$} \\
\hline & 1.06 & $\begin{array}{l}1.01- \\
1.11\end{array}$ & 0.015 & 1.04 & $1-1.07$ & 0.046 \\
\hline WC & 1.02 & $1-1.04$ & 0.028 & 1.02 & $1-1.03$ & 0.032 \\
\hline $\mathrm{HC}$ & 1.01 & $\begin{array}{l}0.99- \\
1.04\end{array}$ & 0.219 & 1.01 & $\begin{array}{l}0.99- \\
1.03\end{array}$ & 0.205 \\
\hline WHR & 8.17 & $\begin{array}{l}1.22- \\
54.96\end{array}$ & 0.031 & 7.13 & $\begin{array}{l}0.81- \\
62.50\end{array}$ & 0.076 \\
\hline WhtR & 1.04 & $\begin{array}{l}1.01- \\
1.07\end{array}$ & 0.010 & 1.02 & $1-1.05$ & 0.033 \\
\hline MAC & 1.01 & $\begin{array}{l}0.96- \\
1.05\end{array}$ & 0.816 & 1.02 & $\begin{array}{l}0.97- \\
1.06\end{array}$ & 0.478 \\
\hline Demispan & 0.97 & $\begin{array}{l}0.93- \\
1.01\end{array}$ & 0.177 & 1.01 & $\begin{array}{l}0.98- \\
1.05\end{array}$ & 0.475 \\
\hline \multicolumn{7}{|l|}{ Disease characteristics } \\
\hline Family history of CVD & 1.59 & $\begin{array}{l}1.08- \\
2.34\end{array}$ & 0.018 & 1.64 & $\begin{array}{l}1.15- \\
2.34\end{array}$ & 0.006 \\
\hline DM & 2.52 & $\begin{array}{l}1.60- \\
3.96\end{array}$ & < 0.001 & 3.46 & $\begin{array}{l}2.35- \\
5.08\end{array}$ & < 0.001 \\
\hline HTN & 1.24 & $\begin{array}{l}0.83- \\
1.86\end{array}$ & 0.300 & 2.14 & $\begin{array}{l}1.48- \\
3.10\end{array}$ & $\dot{0} .001$ \\
\hline Dyslipidemia & 1.21 & $\begin{array}{l}0.71- \\
2.07\end{array}$ & 0.480 & 2.56 & $\begin{array}{l}0.94- \\
6.96\end{array}$ & 0.066 \\
\hline MS & 1.58 & $\begin{array}{l}0.89- \\
2.81\end{array}$ & 0.115 & 2.05 & $\begin{array}{l}1.24- \\
3.41\end{array}$ & 0.005 \\
\hline \multicolumn{7}{|l|}{ Psychological factors } \\
\hline Depression score & 1.01 & $\begin{array}{l}0.99- \\
1.03\end{array}$ & 0.419 & 1.02 & $1-1.03$ & 0.029 \\
\hline \multicolumn{7}{|c|}{$\begin{array}{l}\text { Abbreviations: PAL: physical activity level; BMI: body mass index; WC: waist circumference; HC: hip } \\
\text { circumference; WHR: waist-to-hip ratio; WHtR: waist-to-height ratio; MAC: mid-upper arm } \\
\text { circumference; CVD: cardiovascular disease; DM: diabetes mellitus; HTN: hypertension; MS: metabolic } \\
\text { syndrome; HR: hazard ratio, Cl: confidence interval. }\end{array}$} \\
\hline \multicolumn{7}{|c|}{$\begin{array}{l}\text { Data presented as mean } \pm \text { standard deviations or median (interquartile range). Independent sample t- } \\
\text { test was used where appropriate. }\end{array}$} \\
\hline \multicolumn{7}{|c|}{$\begin{array}{l}\text { The data of education }(n=38) \text {, WC }(n=7) \text {, WHR }(n=7) \text {, MAC }(n=4) \text {, demispan }(n=19) \text {, WBC }(n=113) \text {, } \\
\text { family history of CVD }(n=71) \text {, DM }(n=4), \operatorname{HTN}(n=1) \text {, dyslipidemia }(n=4) \text { and MS }(n=3) \text { were } \\
\text { missed for study participants. }\end{array}$} \\
\hline \multicolumn{7}{|c|}{$\begin{array}{l}\text { THR was adjusted for age and significant parameters in univariate (including diabetes mellitus and } \\
\text { family history of cardiovascular disease). }\end{array}$} \\
\hline
\end{tabular}




\begin{tabular}{|c|c|c|c|c|c|c|}
\hline \multirow{2}{*}{$\begin{array}{l}\text { Variable } \\
\text { Anxiety score }\end{array}$} & \multicolumn{3}{|c|}{ Male $(n=3560)$} & \multicolumn{3}{|c|}{ Female $(n=5080)$} \\
\hline & 1.01 & $\begin{array}{l}0.99- \\
1.03\end{array}$ & 0.349 & 1.03 & $\begin{array}{l}1.01- \\
1.04\end{array}$ & $<.001$ \\
\hline \multicolumn{7}{|c|}{$\begin{array}{l}\text { Abbreviations: PAL: physical activity level; BMI: body mass index; WC: waist circumference; HC: hip } \\
\text { circumference; WHR: waist-to-hip ratio; WHtR: waist-to-height ratio; MAC: mid-upper arm } \\
\text { circumference; CVD: cardiovascular disease; DM: diabetes mellitus; HTN: hypertension; MS: metabolic } \\
\text { syndrome; HR: hazard ratio, Cl: confidence interval. }\end{array}$} \\
\hline \multicolumn{7}{|c|}{$\begin{array}{l}\text { Data presented as mean } \pm \text { standard deviations or median (interquartile range). Independent sample } t \text { - } \\
\text { test was used where appropriate. }\end{array}$} \\
\hline \multicolumn{7}{|c|}{$\begin{array}{l}\text { The data of education }(n=38) \text {, WC }(n=7) \text {, WHR }(n=7) \text {, MAC }(n=4) \text {, demispan }(n=19) \text {, WBC }(n=113) \text {, } \\
\text { family history of CVD }(n=71), \text { DM }(n=4), \operatorname{HTN}(n=1) \text {, dyslipidemia }(n=4) \text { and MS }(n=3) \text { were } \\
\text { missed for study participants. }\end{array}$} \\
\hline † HR was a & sta & $\mathrm{m}$ & iv & ing & ete & \\
\hline
\end{tabular}

\section{Socio-demographics and lifestyle characteristics}

After adjustment of confounding factors, age was positively associated with CVD risk in both genders; though, higher education level was negatively associated with CVD risk only among females. Also, higher PAL was negatively associated with CVD risk in two sexes (HR and $95 \% \mathrm{Cl}: 0.40,0.18-0.85$ in males; $0.28,0.11-0.70$ in females, $P<0.05$ ).

\section{Anthropometric measurements}

Among anthropometric criteria, BMI, WC and WHtR were directly associated with CVD risk among two genders $(P<0.05)$; although, WHR and CVD risk had positive association only in males (HR: $8.17,95 \% \mathrm{Cl}$ : $1.22-54.96, P<0.05)$.

\section{Disease characteristics}

The presence of the FH of CVD (HR and 95\% Cl: 1.59, 1.08-2.34 in males; 1.64, 1.15-2.34 in females, $P<$ $0.05)$ and DM (HR and 95\% Cl: 2.52, 1.60-3.96 in males; 3.46, 2.5-5.08 in females, $P<0.001)$ were positively associated with CVD risk among both males and females. Even though, HTN (HR and 95\% Cl: $2.14,1.48-3.10, P<0.001$ ), and MS (HR and 95\% Cl: 2.05, 1.24-3.41, $P=0.005$ ) had positive association with CVD risk only among women.

\section{Psychological factors}

Both of the depression and anxiety scores were directly associated with CVD risk among women.

\section{Discussion}

In the current study, the association of several risk factors including socio-demographic, lifestyle, psychological, anthropometric factors, and underlying diseases with CVD risk was evaluated in a large cohort-design study. We observed significant direct correlations of age, BMI, WC, WHtR, FH of CVD and 
DM and also negative correlation of PAL with the risk of CVD events among both genders. WHR increased the risk of CVD in males, while education played a protective role against CVD among females. In addition, higher CVD incidence was in a relationship with some other underlying disorders including HTN, MS, depression and anxiety in females. There are various reports about the different risk factors and their effects on CVD incidence (10). Cardiovascular risk factors can be categorized as unmodifiable, modifiable, and behavioral risk factors (35). In the present study, we defined the correlations between some risk factors and CVD incidence in a 6 years follow-up cohort study. All of these impressive risk factors are categorized as modifiable risk factors, except for age and positive $\mathrm{FH}$, and should be concerned in the policy of the governments (35). As well, preventive medicine should be at attention for people with positive $\mathrm{FH}$ and ageing process (35).

This study has shown that WHR is the best anthropometric measure as far better as BMI, WC and WHtR to use in clinic to recognizing subjects with risk factors for CVD; also, it was the most effective risk factor for CVD by the greatest HR. Filippatos et al. have shown that anthropometric indices (BMI, WHR, WC, and WHR, WHtR) were autonomously associated with the 10-year CVD risk (36). Individuals with different ethnicities have different body characteristics (37) and it's so crucial to clarify easy and useful anthropometric measurements for screening and pre-screening of subjects particularly those with higher metabolic risk in different populations. As a result, Ethnicity should be integrated into CVD assessment and this area (Ethnic Specific) in the case of CVD prevention and treatment strategies need further studies and should be more developed (38). Few studies have investigated the relationships between anthropometric measurements with common cardiovascular risk factors in Iran (39-41) and we want to determine the best anthropometric measurements that predict CVD in a longitudinal study. Although BMI analysis is simple and convenient to monitor, many clinical and metabolic studies have revealed that, when obesity is defined just based on BMI alone, it considers the heterogeneous condition, which patients with a close BMI may have distinct metabolic and CVD features $(42,43)$. Esmaillzadeh et al. in a crosssectional survey has demonstrated that WHR is a better predictor for CV risk factors rather than BMI, WHtR and WC in adult men of Tehran (a city of Iran) (41). In a cross-sectional study, they have represented that WC is the best screening measure for CVD risk factors, in the adult population of Tehranian women (40). Yan et al. have supported the WHR is useful for evaluating atherosclerotic burden in obesity screening and clinical researches. They showed that the elevated CVD risk associated with abdominal obesity may be mediated in part by the raised anatomic extent of atherosclerotic vascular disorder (44). In a Multi-Ethnic Study in 52 countries, the data have demonstrated that by redefinition of overweight and obesity criteria's based on WHR instead of BMI, the number of people in the worldwide who categorized at risk of heart attack will be increased threefold (45) and it was a significant predictor of myocardial infarction among both genders without an enlarged WC in adjusted analyses (46). Sehested et al. illustrated that in various forms of obesity and overweight measures, WHR was the only meaningful predictor of the incident of CVD, and the relationship between WHR and risk of CVD was refereed by noted CVD risk factors (47). Simpson et al. in a cohort study have revealed that WHR was positively related to all main cause mortality for both genders (48). However, WC, not WHR in some communities $(49,50)$, and WHtR in others $(51,52)$ have been suggested as a better screening tool for 
CVD risk factors. Our findings showed that WHR is the best anthropometric index for identifying men with risk factors for CVD in Iranian males, in consent to Esmaillzadeh et al. study (41); even though, in females of MASHD study, BMI was the most effective anthropometric measurement as CVD risk factor (HR and $95 \% \mathrm{Cl}: 1.04,1-1.07)$, in contrast to women of Tehran (40).

We also found that DM was associated with nearly 2 and 3 folds higher CVD risk in males and females of the study, respectively. DM is associated with micro- and macro-angiopathies, systemic inflammation and oxidative stress which predispose the patients for developing CVD events and exacerbating the atherogenesis process (53-56). Because of the elevation of inflammatory biochemical markers like high sensitivity C-reactive protein (hs-CRP) and fibrinogen, which was reported in new-onset DM patients (57). As well, these biomarkers are enhanced in CVD patients $(57,58)$. Ho et al. showed in a cohort study in women with average of 8.3 years follow-up that DM patients had the similar risk for incidence of stroke (a type of CVD) compared to patients who had a history of previous stroke (59). Also, Wannamethee et al. showed in a cohort design study of men (60-79 years old) that suffering from DM increased the incidence of coronary heart disease (CHD) (60). These findings agree with our results about two genders.

MS increases the risk of CVD (particularly coronary artery disease) or stroke by three folds (28). In a 2018 systematic review, the prevalence of MS was reported up to 42 percent in the Iranian population and $15.8 \%$ of CVD burden in the Middle East was attributed to this risk factor (61). An analysis of the participants of Tehran Lipid and Glucose study showed that MS which was defined based on IDF criteria increased the risk of CVD development only in a woman (62). Our results illustrated the same findings and showed that MS was considered as a major CVD risk factor only in women. Also, in our population HTN associated with higher CVD events only in women; though, WC and DM were risk factors in both genders and dyslipidemia did not enhance the risk of CVD in both sexes. Therefore, we can imply that probably hypertension played a major role in the positive association of MS and CVD risk among females of the study. However, in other countries HTN was a CVD risk factor in males too; for instance, Sesso et al. have demonstrated in a median follow-up of 10.8 years of United States males that the average of SBP, DBP and mean arterial pressure (MAP) are strong predictor for CVD incidence in men, with higher relative risk (RR) in men younger than 60 comparing to $\geq 60$ years old (63). These differences might be related to the sociocultural, ethnic and genetic determinants of different regions, worldwide (64-67). Also, in a research on the Iranian population of Tehran, it was found that female gender is a protective factor in developing HTN (68); this contrast finding in two regions of Iran (Mashhad and Tehran) may be related to lifestyle and diet habits (66).

We mentioned to genetic predisposition as an impressive factor for occurrence of CVD (67). Genetic predisposition affects the incidence of CVD by multigenic pathways $(69,70)$; hence, pharmacogenetics have tried to treat CVD by affecting different genes which induce CVD (70). In this study, we did not evaluate the different genes that impress CVD incidence; though, we assessed the influence of presence of positive $\mathrm{FH}$ of CVD as a possible predictor of CVD. Glowinska et al. demonstrated that children and adolescents with positive FH of CVD had higher BMI and lipoprotein-A level than persons with negative FH (71). Also, Wright et al. showed the effect of positive FH of CVD on the body response to stressful 
situations (72). They showed that persons with positive FH had higher SBP and DBP and poorer BP recovery after stress (72). In addition, Scottish people with positive FH had higher ASSIGN score (a scoring system for CVD risk) (73). Thereby, the influence of positive FH on the CVD occurrence is explained by its effect on the presence of other CVD risk factors like high BMI, lipoprotein-A level and BP.

Another finding of this study is the major protective effect of PAL against CVD incidence. This finding was expected according to previous studies $(74,75)$. In a 5-years cohort study of population of Denmark, it was shown that by increasing the PAL, weight, WC and DBP were decreased in both men and women, and also, HDL-C was increased in men (74). Recently, in a systematic review and meta-analysis it was demonstrated that sedentary behaviors like sitting time (ST) and television time (TT) per day had a dosedependent association with CVD mortality in inactive persons (9-32\% higher risk for ST and 3-59\% higher risk for TT) (75). Therefore, enhancing the PAL can strongly reduce the CVD risk and mortality (75, 76).

The strength of the present study was documenting and following up the traditional risk factors for CVD in detail in a large population for the first time in Iran. The large sample size and type of this study make our results useful as baseline data for future research, especially focusing on WHR as a screening method for abdominal obesity. Since, World Health Organization (WHO) advocates the use of some anthropometric measurements as a screening resource for individuals under cardiometabolic risk (77). Nevertheless, there are several potential limitations that need to be addressed; although we considered all the possible risk factors in our analysis, residual unknown confounders may be still present. It is possible that genetic and environmental factors including lifestyle characteristics and certain dietary habits influence the relationships between the cardiovascular event and its risk factors.

\section{Conclusion:}

This 6-years follow-up study would provide a useful resource to help public health care and epidemiology. The considerable effect of ethnicity and genetics in CVD progression highlights the importance of evolving local cardiovascular risk calculator based on local population-based studies. Moreover, the findings of these studies improve screening, preventive and therapeutic approaches, and guidelines. However, further national and ethical studies are needed to confirm these observations and to determine the differences in the importance of risk factors among the population.

\section{Declarations}

\section{Ethics approval and consent to participate}

Informed consent was obtained from all subjects using protocols approved by the Ethics Committee of the Mashhad University of Medical Sciences. All participants were able to read and understand and were willing to provide written, informed consent.

\section{Consent to publish}


Not applicable

\section{Availability of data and materials}

Data sharing not applicable to this article as no datasets were generated or analyzed during the current study.

\section{Competing interests}

The authors declare no conflict of interests.

Funding: Research reported in this publication was supported by the Mashhad University of Medical Sciences, Mashhad, Iran.

\section{Acknowledgment}

We would like to thank Mashhad University of Medical Sciences Research council for their financial support. The study was approved by the Ethics Committee of Mashhad University of Medical Sciences (Ethics number: IR.MUMS.REC.1386.250).

\section{Authors' Contributions}

We declare that We contributed significantly towards the research study i.e., (a) conception, design and/or analysis and interpretation of data and to (b) drafting the article or revising it critically for important intellectual content and on (c) final approval of the version to be published.

\section{Conflict of interest}

The authors have no conflict of interest to disclose.

\section{References}

1. Pagidipati NJ, Gaziano TA. Estimating deaths from cardiovascular disease: a review of global methodologies of mortality measurement. Circulation. 2013;127(6):749-56.

2. Laslett LJ, Alagona P, Clark BA, Drozda JP, Saldivar F, Wilson SR, et al. The worldwide environment of cardiovascular disease: prevalence, diagnosis, therapy, and policy issues: a report from the American College of Cardiology. Journal of the American College of Cardiology. 2012;60(25 Supplement):S1S49.

3. Nichols M, Townsend N, Scarborough P, Rayner M. Cardiovascular disease in Europe 2014: epidemiological update. European heart journal. 2014;35(42):2950-9.

4. Association AH. Heart Disease and Stroke Statistics 2017 At-a-Glance. on-line at: http://www heart org/idc/groups/ahamahpublic/@wcm/@sop/@smd/documents/downloadable/ucm2017. 
5. Benjamin EJ MP, Alonso A, Bittencourt MS, Callaway CW, Carson AP, et al. Heart Disease and Stroke Statistics-2019 Update: A Report From the American Heart Association. Circulation. 2017.

6. Brown JR, O'Connor GT. Coronary heart disease and prevention in the United States. New England Journal of Medicine. 2010;362(23):2150-3.

7. Sadeghi M, Haghdoost AA, Bahrampour A, Dehghani M. Modeling the burden of cardiovascular diseases in Iran from 2005 to 2025: The impact of demographic changes. Iranian journal of public health. 2017;46(4):506.

8. Forouzanfar MH, Sepanlou SG, Shahraz S, BESc PN, Pourmalek F, Lozano R, et al. Evaluating causes of death and morbidity in Iran, global burden of diseases, injuries, and risk factors study 2010. Archives of Iranian medicine. 2014;17(5):304.

9. Zhao D, Liu J, Xie W, Qi Y. Cardiovascular risk assessment: a global perspective. Nature Reviews Cardiology. 2015;12(5):301.

10. Matthews KA, Sowers MF, Derby CA, Stein E, Miracle-McMahill H, Crawford SL, et al. Ethnic differences in cardiovascular risk factor burden among middle-aged women: Study of Women's Health Across the Nation (SWAN). American heart journal. 2005;149(6):1066-73.

11. Amini M, Esmaeilzadeh-bahabadi S, Avan A, Gholoobi A, Ghasemi F, Mirhafez SR, et al. Paraoxonase1 Q192R polymorphism and its association with hs-CRP and fasting blood glucose levels and risk of coronary artery disease. Diabetes \& Metabolic Syndrome: Clinical Research \& Reviews. 2019;13(2):1053-7.

12. Arasteh S, Moohebati M, Avan A, Esmaeili H, Ghazizadeh H, Mahdizadeh A, et al. Serum level of gamma-glutamyl transferase as a biomarker for predicting stenosis severity in patients with coronary artery disease. Indian heart journal. 2018;70(6):788-92.

13. Rokni H, Moohebati M, Saberi-Karimian M, Mirhafez SR, Ghazizadeh H, Laal-Vazifeh A, et al. A study of difference in serum 25-hydroxyvitamin $D$ concentrations in patients with angiographically-defined coronary disease and healthy subjects. Diabetes \& Metabolic Syndrome: Clinical Research \& Reviews. 2018;12(5):683-7.

14. Barati E, Ghazizadeh H, Sadabadi F, Kazemi E, Ferns GA, Avan A, et al. Association of the IL6 Gene Polymorphism with Component Features of Metabolic Syndrome in Obese Subjects. Biochemical genetics. 2019:1-14.

15. Eshaghi FS, Ghazizadeh H, Nooreini SK, Timar A, Esmaeily H, Mehramiz M, et al. Association of a genetic variant in AKT1 gene with features of the metabolic syndrome. Genes \& Diseases. 2019.

16. Ghazizadeh H, Avan A, Fazilati M, Azimi-Nezhad M, Tayefi M, Ghasemi F, et al. Association of rs6921438 A<G with serum vascular endothelial growth factor concentrations in patients with metabolic syndrome. Gene. 2018;667:70-5.

17. Daloee MH, Avan A, Mirhafez SR, Kavousi E, Hasanian-Mehr M, Darroudi S, et al. Impact of cigarette smoking on serum pro-and anti-inflammatory cytokines and growth factors. American journal of men's health. 2017;11(4):1169-73. 
18. Vishram J. Prognostic interactions between cardiovascular risk factors. Dan Med J. 2014;61(7):B4892.

19. Azarpazhooh MR, Etemadi MM, Donnan GA, Mokhber N, Majdi MR, Ghayour-Mobarhan M, et al. Excessive incidence of stroke in Iran: evidence from the Mashhad Stroke Incidence Study (MSIS), a population-based study of stroke in the Middle East. Stroke. 2010;41(1):e3-e10.

20. Daryani A, Berglund L, Andersson $\AA$, Kocturk T, Becker W, Vessby B. Risk factors for coronary heart disease among immigrant women from Iran and Turkey, compared to women of Swedish ethnicity. Ethnicity \& disease. 2005;15(2):213-20.

21. Ghayour-Mobarhan M, Moohebati M, Esmaily H, Ebrahimi M, Parizadeh SMR, Heidari-Bakavoli AR, et al. Mashhad stroke and heart atherosclerotic disorder (MASHAD) study: design, baseline characteristics and 10-year cardiovascular risk estimation. International journal of public health. 2015;60(5):561-72.

22. Luepker RV, Murray DM, Jacobs Jr DR, Mittelmark MB, Bracht N, Carlaw R, et al. Community education for cardiovascular disease prevention: risk factor changes in the Minnesota Heart Health Program. American journal of public health. 1994;84(9):1383-93.

23. Prineas RJ, Crow RS, Zhang Z-M. The Minnesota code manual of electrocardiographic findings: Springer Science \& Business Media; 2009.

24. Mahmood SS, Levy D, Vasan RS, Wang TJ. The Framingham Heart Study and the epidemiology of cardiovascular disease: a historical perspective. The Lancet. 2014;383(9921):999-1008.

25. Mancia G, De Backer G, Dominiczak A, Cifkova R, Fagard R, Germano G, et al. 2007 Guidelines for the management of arterial hypertension: The Task Force for the Management of Arterial Hypertension of the European Society of Hypertension (ESH) and of the European Society of Cardiology (ESC). European heart journal. 2007;28(12):1462-536.

26. Grundy SM. An International Atherosclerosis Society Position Paper: global recommendations for the management of dyslipidemia. Journal of clinical lipidology. 2013 Nov-Dec;7(6):561-5. PubMed PMID: 24314355. Epub 2013/12/10. eng.

27. Alberti K, Eckel RH, Grundy SM, Zimmet PZ, Cleeman JI, Donato KA, et al. Harmonizing the metabolic syndrome: a joint interim statement of the international diabetes federation task force on epidemiology and prevention; national heart, lung, and blood institute; American heart association; world heart federation; international atherosclerosis society; and international association for the study of obesity. Circulation. 2009;120(16):1640-5.

28. Alberti KGMM, Zimmet P, Shaw J. Metabolic syndrome-a new world-wide definition. A consensus statement from the international diabetes federation. Diabetic medicine. 2006;23(5):469-80.

29. Steer RA, Ranieri WF, Beck AT, Clark DA. Further evidence for the validity of the Beck Anxiety Inventory with psychiatric outpatients. Journal of anxiety disorders. 1993;7(3):195-205.

30. Beck AT, Ward CH, Mendelson M, Mock J, Erbaugh J. An inventory for measuring depression. Archives of general psychiatry. 1961;4(6):561-71. 
31. James WPT, Schofield EC. Human energy requirements. A manual for planners and nutritionists: Oxford University Press; 1990.

32. Zomorrodian D, Khajavi-Rad A, Avan A, Ebrahimi M, Nematy M, Azarpazhooh MR, et al. Metabolic syndrome components as markers to prognosticate the risk of developing chronic kidney disease: evidence-based study with 6492 individuals. Journal of epidemiology and community health. 2015 Jun;69(6):594-8. PubMed PMID: 25631859. Epub 2015/01/30. eng.

33. Emamian M, Avan A, Pasdar A, Mirhafez SR, Sadeghzadeh M, Moghadam MS, et al. The lipoprotein lipase S447X and cholesteryl ester transfer protein rs5882 polymorphisms and their relationship with lipid profile in human serum of obese individuals. Gene. 2015 Mar 10;558(2):195-9. PubMed PMID: 25579610. Epub 2015/01/13. eng.

34. Emamian M, Hasanian SM, Tayefi M, Bijari M, Movahedian Far F, Shafiee M, et al. Association of hematocrit with blood pressure and hypertension. Journal of clinical laboratory analysis. 2017 Nov;31(6). PubMed PMID: 28105697. Epub 2017/01/21. eng.

35. Mohammadnezhad M, Mangum T, May W, Lucas JJ, Ailson S. Common modifiable and nonmodifiable risk factors of cardiovascular disease (CVD) among Pacific countries. World Journal of Cardiovascular Surgery. 2016;6(11):153.

36. Filippatos TD, Kyrou I, Georgousopoulou EN, Chrysohoou C, Kouli G-M, Tsigos C, et al. Modeling anthropometric indices in relation to 10-year (2002-2012) incidence of cardiovascular disease, among apparently healthy individuals: The ATTICA study. Diabetes \& Metabolic Syndrome: Clinical Research \& Reviews. 2017;11:S789-S95.

37. Carroll JF, Chiapa AL, Rodriquez M, Phelps DR, Cardarelli KM, Vishwanatha JK, et al. Visceral fat, waist circumference, and BMI: impact of race/ethnicity. Obesity. 2008;16(3):600-7.

38. Goh LG, Dhaliwal SS, Welborn TA, Lee AH, Della PR. Ethnicity and the association between anthropometric indices of obesity and cardiovascular risk in women: a cross-sectional study. BMJ open. 2014;4(5):e004702.

39. Mellati AA, Mousavinasab SN, Sokhanvar S, Kazemi SAN, Esmaill MH, Dinmohamadi H. Correlation of anthropometric indices with common cardiovascular risk factors in an urban adult population of Iran: data from Zanjan Healthy Heart Study. Asia Pacific journal of clinical nutrition. 2009;18(2):217.

40. Esmaillzadeh A, Mirmiran P, Azizi F. Comparative evaluation of anthropometric measures to predict cardiovascular risk factors in Tehranian adult women. Public health nutrition. 2006;9(1):61-9.

41. Esmaillzadeh A, Mirmiran P, Azizi F. Waist-to-hip ratio is a better screening measure for cardiovascular risk factors than other anthropometric indicators in Tehranian adult men. International journal of obesity. 2004;28(10):1325-32.

42. Keys A, Fidanza F, Karvonen MJ, Kimura N, Taylor HL. Indices of relative weight and obesity. International journal of epidemiology. 2014 Jun;43(3):655-65. PubMed PMID: 24691951. Epub 2014/04/03. eng.

43. Neeland IJ, Poirier P, Després J-P. Cardiovascular and metabolic heterogeneity of obesity: clinical challenges and implications for management. Circulation. 2018;137(13):1391-406. 
44. Yan RT, Yan AT, Anderson TJ, Buithieu J, Charbonneau F, Title L, et al. The differential association between various anthropometric indices of obesity and subclinical atherosclerosis. Atherosclerosis. 2009;207(1):232-8.

45. Yusuf S, Hawken S, Ounpuu S, Bautista L, Franzosi MG, Commerford P, et al. Obesity and the risk of myocardial infarction in 27000 participants from 52 countries: a case-control study. The Lancet. 2005;366(9497):1640-9.

46. Egeland GM, Igland J, Vollset SE, Sulo G, Eide GE, Tell GS. High population attributable fractions of myocardial infarction associated with waist-hip ratio. Obesity. 2016;24(5):1162-9.

47. Sehested TS, Hansen TW, Olsen MH, Abildstrøm SZ, Rasmussen S, Ibsene H, et al. Measures of overweight and obesity and risk of cardiovascular disease: a population-based study. European Journal of Cardiovascular Prevention \& Rehabilitation. 2010;17(4):486-90.

48. Simpson JA, MacInnis RJ, Peeters A, Hopper JL, Giles GG, English DR. A comparison of adiposity measures as predictors of all-cause mortality: the Melbourne Collaborative Cohort Study. Obesity. 2007;15(4):994-1003.

49. Park S-H, Choi S-J, Lee K-S, Park H-Y. Waist circumference and waist-to-height ratio as predictors of cardiovascular disease risk in Korean adults. Circulation Journal. 2009;73(9):1643-50.

50. Wang Z, Hoy W. Waist circumference, body mass index, hip circumference and waist-to-hip ratio as predictors of cardiovascular disease in Aboriginal people. European journal of clinical nutrition. 2004;58(6):888.

51. Zhu Q, Shen F, Ye T, Zhou Q, Deng H, Gu X. Waist-to-height ratio is an appropriate index for identifying cardiometabolic risk in $\mathrm{C}$ hinese individuals with normal body mass index and waist

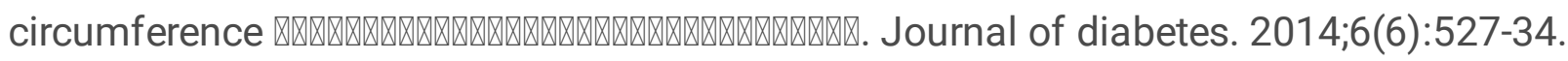

52. Lin W, Lee L, Chen C, Lo H, Hsia H, Liu I, et al. Optimal cut-off values for obesity: using simple anthropometric indices to predict cardiovascular risk factors in Taiwan. International journal of obesity. 2002;26(9):1232.

53. Low Wang CC, Hess CN, Hiatt WR, Goldfine AB. Clinical update: cardiovascular disease in diabetes mellitus: atherosclerotic cardiovascular disease and heart failure in type 2 diabetes mellitusmechanisms, management, and clinical considerations. Circulation. 2016;133(24):2459-502.

54. Leon BM, Maddox TM. Diabetes and cardiovascular disease: Epidemiology, biological mechanisms, treatment recommendations and future research. World journal of diabetes. 2015;6(13):1246.

55. Rawshani A, Rawshani A, Franzén S, Eliasson B, Svensson A-M, Miftaraj M, et al. Mortality and cardiovascular disease in type 1 and type 2 diabetes. New England Journal of Medicine. 2017;376(15):1407-18.

56. Petrie JR, Guzik TJ, Touyz RM. Diabetes, hypertension, and cardiovascular disease: clinical insights and vascular mechanisms. Canadian Journal of Cardiology. 2018;34(5):575-84.

57. Haffner SM. The metabolic syndrome: inflammation, diabetes mellitus, and cardiovascular disease. The American journal of cardiology. 2006;97(2):3-11. 
58. Avan A, Tavakoly Sany SB, Ghayour-Mobarhan M, Rahimi HR, Tajfard M, Ferns G. Serum C-reactive protein in the prediction of cardiovascular diseases: Overview of the latest clinical studies and public health practice. Journal of cellular physiology. 2018;233(11):8508-25.

59. Ho JE, Paultre F, Mosca L. Is diabetes mellitus a cardiovascular disease risk equivalent for fatal stroke in women? Data from the Women's Pooling Project. Stroke. 2003;34(12):2812-6.

60. Wannamethee SG, Shaper AG, Whincup PH, Lennon L, Sattar N. Impact of diabetes on cardiovascular disease risk and all-cause mortality in older men: influence of age at onset, diabetes duration, and established and novel risk factors. Archives of internal medicine. 2011;171(5):404-10.

61. Ansarimoghaddam A, Adineh HA, Zareban I, Iranpour S, HosseinZadeh A, Kh F. Prevalence of metabolic syndrome in Middle-East countries: Meta-analysis of cross-sectional studies. Diabetes \& Metabolic Syndrome: Clinical Research \& Reviews. 2018;12(2):195-201.

62. Amouzegar A, Mehran L, Hasheminia M, Kheirkhah Rahimabad P, Azizi F. The predictive value of metabolic syndrome for cardiovascular and all-cause mortality: Tehran Lipid and Glucose Study. Diabetes/metabolism research and reviews. 2017;33(1):e2819.

63. Sesso HD, Stampfer MJ, Rosner B, Hennekens CH, Gaziano JM, Manson JE, et al. Systolic and diastolic blood pressure, pulse pressure, and mean arterial pressure as predictors of cardiovascular disease risk in men. Hypertension. 2000;36(5):801-7.

64. Winkleby MA, Kraemer HC, Ahn DK, Varady AN. Ethnic and socioeconomic differences in cardiovascular disease risk factors: findings for women from the Third National Health and Nutrition Examination Survey, 1988-1994. Jama. 1998;280(4):356-62.

65. Kandula N, Ahmed M, Dodani S, Gupta L, Hore P, Kanaya A, et al. Cardiovascular disease \& cancer risk among South Asians: impact of sociocultural influences on lifestyle and behavior. Journal of immigrant and minority health. 2019;21(1):15-25.

66. Deen JF, Adams AK, Fretts A, Jolly S, Navas-Acien A, Devereux RB, et al. Cardiovascular disease in American Indian and Alaska native youth: unique risk factors and areas of scholarly need. Journal of the American Heart Association. 2017;6(10):e007576.

67. Ehret GB, Munroe PB, Rice KM, Bochud M, Johnson AD, Chasman DI, et al. Genetic variants in novel pathways influence blood pressure and cardiovascular disease risk. Nature. 2011;478(7367):103.

68. Abdi H, Amouzegar A, Tohidi M, Azizi F, Hadaegh F. Blood pressure and hypertension: Findings from 20 years of the Tehran Lipid and Glucose Study (TLGS). International journal of endocrinology and metabolism. 2018;16(4 Suppl).

69. Friedmann T. Approaches to gene therapy of complex multigenic diseases: cancer as a model and implications for cardiovascular disease and diabetes. Annals of medicine. 1992;24(5):411-7.

70. Cooke GE. Pharmacogenetics of multigenic disease: heart disease as an example. Vascular pharmacology. 2006;44(2):66-74.

71. Glowinska B, Urban M, Koput A. Cardiovascular risk factors in children with obesity, hypertension and diabetes: lipoprotein (a) levels and body mass index correlate with family history of cardiovascular disease. European journal of pediatrics. 2002;161(10):511-8. 
72. Wright CE, O'Donnell K, Brydon L, Wardle J, Steptoe A. Family history of cardiovascular disease is associated with cardiovascular responses to stress in healthy young men and women. International Journal of Psychophysiology. 2007;63(3):275-82.

73. Woodward M, Brindle P, Tunstall-Pedoe H. Adding social deprivation and family history to cardiovascular risk assessment: the ASSIGN score from the Scottish Heart Health Extended Cohort (SHHEC). Heart. 2007;93(2):172-6.

74. Aadahl M, von Huth Smith L, Pisinger C, Toft U, Glümer C, Borch-Johnsen K, et al. Five-year change in physical activity is associated with changes in cardiovascular disease risk factors: the Inter99 study. Preventive medicine. 2009;48(4):326-31.

75. Ekelund U, Brown WJ, Steene-Johannessen J, Fagerland MW, Owen N, Powell KE, et al. Do the associations of sedentary behaviour with cardiovascular disease mortality and cancer mortality differ by physical activity level? A systematic review and harmonised meta-analysis of data from 850060 participants. British journal of sports medicine. 2019;53(14):886-94.

76. Georgousopoulou EN, Panagiotakos DB, Bougatsas D, Chatzigeorgiou M, Kavouras SA, Chrysohoou C, et al. Physical Activity Level Improves the Predictive Accuracy of Cardiovascular Disease Risk Score: The ATTICA Study (2002-2012). International journal of preventive medicine. 2016;7.

77. Caminha TC, Ferreira HS, Costa NS, Nakano RP, Carvalho RES, Xavier Jr AF, et al. Waist-to-height ratio is the best anthropometric predictor of hypertension: A population-based study with women from a state of northeast of Brazil. Medicine. 2017;96(2). 